\title{
BioLink
}

Jurnal Biologi Lingkungan, Industri, Kesehatan

Available online http://ojs.uma.ac.id/index.php/biolink

\section{ANALISA TINGKAT PENCEMARAN LOGAM BERAT TIMBAL (Pb) DI DAERAH ALIRAN SUNGAI DELI SUMATERA UTARA}

\section{ANALYSIS OF HEAVY METAL POLLUTION (Pb) IN THE FLOW AREAS OF DELI NORTH SUMATRA}

\author{
Suratni Afrianti* dan Julaili Irni \\ Program Studi Agroteknologi, Fakultas Agro Teknologi, Universitas Prima Indonesia \\ Diterima : 10-10-2019; Disetujui : 09-12-19: Diterbitkan : 10-02-2020 \\ *Corresponding author: E-mail: suratniafrianti@unprimdn.ac.id
}

\begin{abstract}
Abstrak
Sungai deli merupakan Darerah Aliran Sungai Pioritas I yang ada Sumatera utara, tingkat aktivitas masyarakat yang ada di sempadan sungai deli tinggi seperti pemukiman, perkantoran, sekolah dan industri, masyarakat berpotensi menghasilkan limbah padat banyak ber muara ke badan sungai sehingga membuat sungai tersebut tercemar, parameter pencemaran adalah logam berat. Tujuan dari penelitian ini adalah menganalisis kandungan $\mathrm{Pb}$ di Sungai Deli dengan menggunakan alat AAS, dari hasil analisis tingkat pencemaran sungai deli maka didapatkan Hasil Analisa Timbal $(\mathrm{Pb})$ dari hulu hingga hilir adalah nilai rata rata $0,003 \mathrm{ppm}$ hal ini bearti pencemaran timbal $(\mathrm{Pb})$ yang ada di sungai deli masih tergolong rendah atau belum tercemar oleh logam berat timbal $(\mathrm{Pb})$ karena menurut PP RI NO 82 TAHUN 2001 tentang Pengelolaan Kualitas Air dan pengendalian pencemaran air baku mutu $0,03 \mathrm{ppm}$.
\end{abstract}

Kata Kunci: DAS, Pencemaran, Sampah, Timbal, Pengelolan

\begin{abstract}
The Deli river is the Pioritas I River Basin in North Sumatra, the level of community activity in the Deli river border is high such as settlements, offices, schools and industries, the community has the potential to produce a lot of solid waste in the estuary to the river body to make the river polluted, parameters pollution is heavy metal. The purpose of this study is to analyze the Pb content in the Deli River using the AAS tool, from the analysis of the deli river pollution level, the Lead Analysis Result (Pb) obtained from upstream to downstream is an average value of $0.003 \mathrm{ppm}$, this means that lead pollution $(\mathrm{Pb})$ in the river Deli is still relatively low or has not been polluted by lead-heavy metals (Pb) because according to Government Regulation No. 82 of 2001 concerning Water Quality Management and quality pollution control of 0.03 ppm standard water.
\end{abstract}

Key Words: DAS, Pollution, Waste, Lead, Management

How to Cite: Afrianti. S. dan Irni, J. (2020). Analisa Tingkat Pencemaran Logam Berat Timbal (Pb) di Daerah Aliran Sungai Deli Sumatera Utara, BioLink: Jurnal Biologi Lingkungan, Industri dan Kesehatan, Vol.6 (2): Hal. 153-161 
Afriati, S. dan Irni, J. Analisa Tingkat Pencemaran Logam Berat (Pb) di Daerah Aliran Sungai Deli Sumatera Utara

PENDAHULUAN

Sungai salah satu sumber daya alam yang di miliki oleh Kota Medan dan sangat dibutuhkan untuk menopang kehidupan, air sungai yang kualitasnya buruk akan berdampak terhapa lingkungan hidup menjadi buruk, sehingga akan mempengaruhi keseimbangan ekosistem dan kehidupan lingkungan hidup lainya. Penurunan kualitas air sungai akan menurunkan daya guna, hasil dan produktivitas selain itu juga akan berdampak terhadap pengurangan daya tampung sungai yang menyebabkan menurunkan kekekayan sumber daya alam yang ada.

Pada saat ini memperoleh kulitas air bersih sesuai standar, sangat susah didapatkan karena kualitas air sungai sudah banyak tercemar oleh bermacammacam limbah dari berbagai hasil aktivitas manusia, mulai bersumber dari limbah industry, domestic dan lainnya, sehingga dampak pontesial yang diberikan terhadap Kualitas dan kuantitas Sumber Daya Alam (SDA) Sungai penurun baik dilihat secara kuantitas maupun kualitas.

Sungai merupakan salah satu air permukaan yang merupakan sumber air untuk kehidupan, peranan sungai sangat penting sehingga harus dipelihara dengan baik, menurut (Mahfudloh, M., \&
Lestari, H. 2017) sungai saat ini banyak yang tercemar akibat adanya aktivitas manusia yang tidak ramah terhadap sungai sehingga membuang limbah tanpa melakukan pengelolaan terlebih dahulu, selain itu masalah sungai saat ini adalah masalah daya tamping sungai yang sudah sangat melebih batas dikutip dari penelitian (Hindriani,

Penurunan kualitas air sungai akan menurunkan fungsi perairan dan mengganggu kehidupan aquatic yang ada didalamnya, dimana kehidupan aquatic mempunyai fungsi masing-masing untuk memjaga keseimbangan lingkungan. Aktivitas manusia adalah penyumbang paling banyak memberikan dampak terhadap peningkatan bahan organik. Bahan organik akan teurai, sehingga menjadi peningkatan unsur fosfor dan nitrogen di perairan.

Menurut (Amalia, G. R. 2013) upaya dalam menjaga sungai atau mengurangi dari pencemaran adalah dengan melakukan upaya pengelolaan dan upaya pemantauan lingkungan hidup terhadap sumber pencemaran, Salah satu upaya pengelolaan sungai adalah mengatasi tingkat penurunan kualitas sungai, penurunan kualitas sungai diantaranya disebabkan oleh masuknya berbagai buangan limbah dari berbagai aktifitas manusia. Rusaknya tatanan lingkungan 
salah salah satu sumber penyebabnya adalah dari logam berat seperti pb. (Diantariani, N. P,.Dkk, 2006). Tujuan penelitian ini adalah menganalisis kandungan $\mathrm{Pb}$ pada air sungai deli Sumatera Utara dan menentukan kualitas air sungai berdasarkan baku mutu PP RI No 82 tahun 2001. Dalam Keputusan Gubenur Sumatera Utara NOMOR 614 /2665/KI TAHUN 2009 Tentang Forum Pengelolaan Daerah Aliran Sungai Wampu, Sungai Dell Dan Sungai Ular. Menyatakan bahwahsanya sungai-sungai ini merupakan Daerah Aliran Sungai (DAS) Prioritas I, perlu pengelolaan secara terpadu dan terkoordinasi, oleh sebab itu maka penelitian sangat penting guna memberikan informasi kepada pemerintah dan masyarakat sekitar mengenai tingkat pencemaran logam berat timbal $(\mathrm{Pb})$ di Sungai Deli Sumatera Utara.

\section{METODE PENELITIAN}

Waktu dan tempat penelitian adalah Bulan Mei - oktober 2019 di Daeral aliran Sungai Deli, Alat dan bahan, Alat yang digunakan terdiri dari, tali berskala, peralatan gelas, peralatan titrasi, botol contoh $250 \mathrm{ml}$, dan $300 \mathrm{ml}, \mathrm{pH}$ meter, GPS, kamera digital, termometer air raksa, oven, kertas label, secchi disk, turbidimeter, neraca analitik, oven serta
AAS

(Atomic

Absorption

Spectrophotometer), eckmen grab, coolbox/ice box, seperangkat komputer dan internet untuk menjalankan software Geographic Information Sistem (GIS), sedangkan bahan yang digunakan terdiri dari air bebas mineral (akuabides), HNO3, larutan $\mathrm{Pb}$, larutan pengencer HNO3 $5 \mathrm{ml}$.

Metode yang digunakan dalam penentuan lokasi sampling untuk pengambilan logam berat timbal adalah "Purpossive Sampling" yaitu cara penentuan titik lokasi pengambilan cuplikan air dengan melihat pertimbangan-pertimbangan yang dilakukan oleh peneliti seperti pertimbangan terhadap kemudahan askes, biaya yang dibutuhkan untuk kelokasi dan waktu yang dibutuhkan dalam penelitian, Purposive sampling menurut Sugiyono adalah teknik penentuan pengambilan sampel dengan pertimbangan tertentu (Sugiyono, 2012), sungai akan di bagi menjadi 3 bagian hulu, tengah dan hilir sungai deli, masingmasing bagian akan di ambil 10 titik sehingga jumlah sampel keseluruhan adalah 30 sampel.

Prosedur Penelitian pengambilan sampel air, Sampel air diambil pada bagian lapisan paling atas atau permukaan sungai dengan menggunakan botol $\pm 250 \mathrm{ml}$ dimasukkan ke dalam 
wadah atau botol polyetilen, kemudian di analisa di laboratorium, Analisis logam berat dengan AAS dilakukan di Balai Penelitian dan Perindustrian Provinsi (GIS)

Sumatera Utara.

Prosedur analisa sampel : Air sungai diambil $50 \mathrm{ml}$ dikeringkan sampai volume 10-15 $\mathrm{ml}$ menggunakan waterbath, kemudian menambahkan $5 \mathrm{ml}$ Tugas ketua adalah Mempersiapkan $\mathrm{HNO}_{3}$, kemudian memanaskan kembali semua kebutuhan penelitian, selama 15 menit, kemudian mengkoordinir tim dalam pelaksanaan

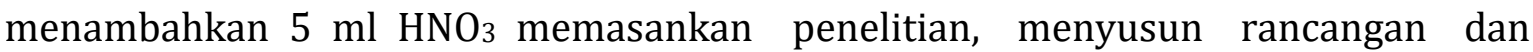
kembali selama 15 menit, selanjutnya hasil akhir luaran penelitian dan dipindahkan ke labu ukur dengan volume menyusun laporan, sedangkan tugas $25 \mathrm{ml}$ dan kemudian sampel air siap di uji anggota adalah membantu ketua tim ke AAS (Husainy.,I.,A., dkk,. 2014). dalam pelaksanaan penelitian,

Analisa selanjutnya dengan melakukan analisis data dan menyusun pengolahan data yaitu membuat lanskap laporan bersama tim.

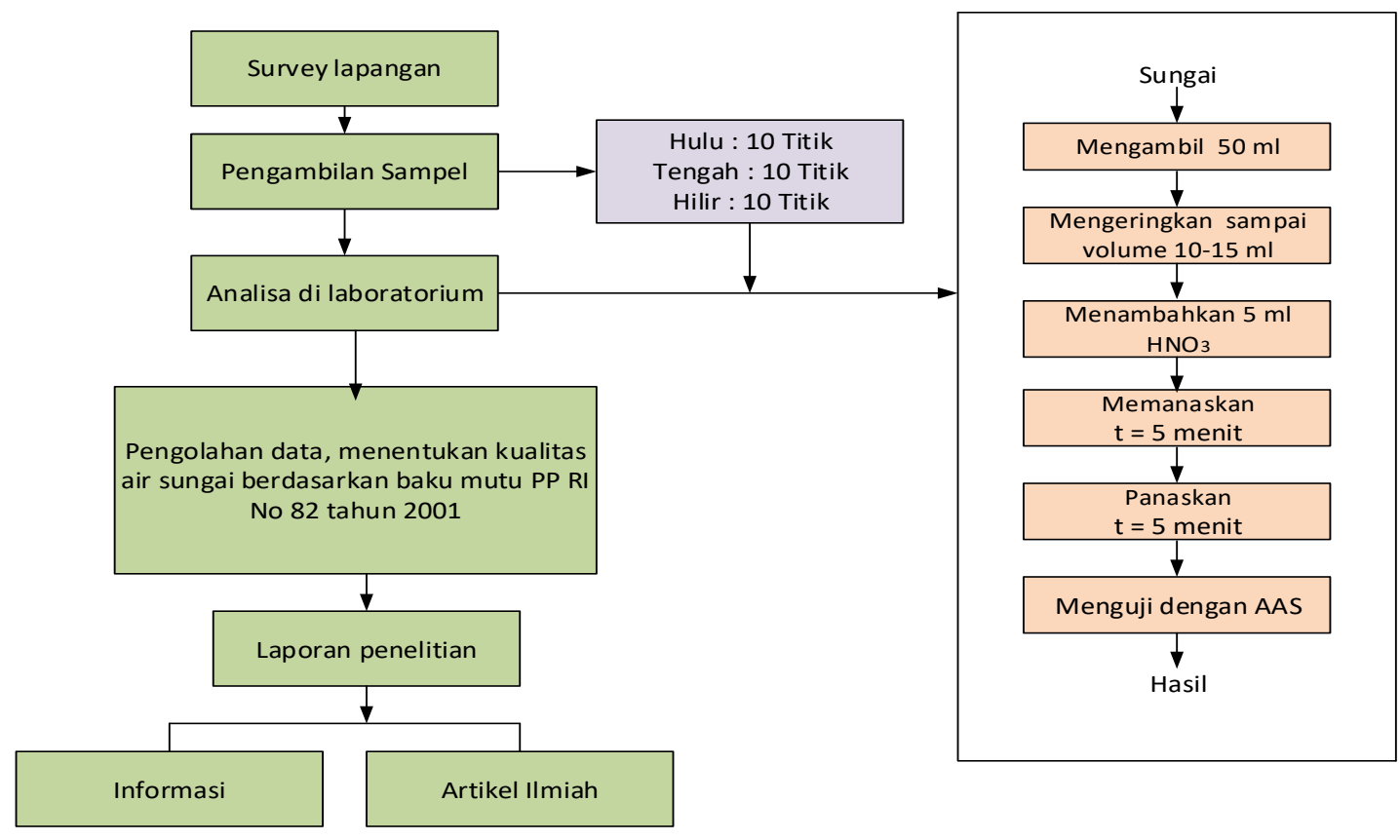

Gambar 1. Blok diagram Prosedur Penelitian 
HASIL DAN PEMBAHASAN

\section{Deskripsi Sungai Deli}

Rona lingkungan yang diamati selama menggunung di sempadan sungai.

penelitian, sepanjang sungai deli banyak aktivitas penduduk seperti pemukiman, sekolah, perkantoran dan industry, saat melakukan sampling, air sungai berwarna keruh dan di sepadan sungai maupun badan sungai banyak ditemukan tumpukan sampah, penyebab hal ini adalah oleh budaya dan kurangnya pengelolaan yang baik oleh masyarakat sekitar sungai dan kurangnya pemantaua yang dilakukan oleh pemerintah setempat, sebagai mana yang dimuat dalam UU No. 18 Tahun 2008 pengelolaan sampah harus yang teratur, total, dan kontiniu yang meliputi manusia terhadap nilai estetika pengurangan dan pengelolaan sampah. lingkungan dan ekosistem alam. Kegiatan pengurangan sampah tersebut Gambaran rona lingkungan bisa di lihat adalah a. pendauran ulang sampah; b. pada gambar dibawah ini. pembatasan timbulang sampah; c.

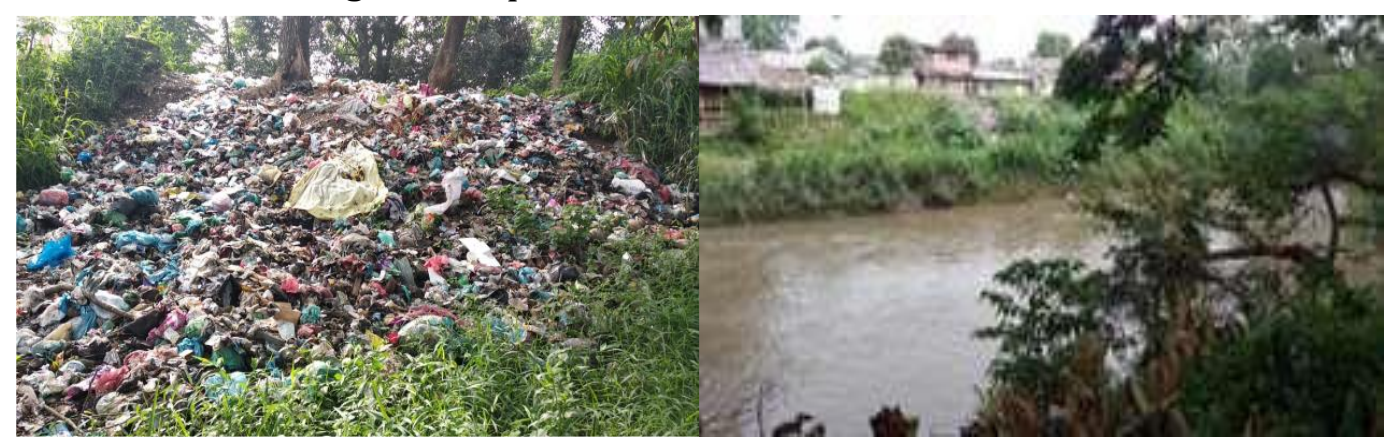

Gambar 2. Rona lingkungan Sungai Deli

Menurut Hutapea, S. (2012) Daerah Sub DAS Deli, Sub DAS Sei Kambing dan Sub Aliran Sungai (DAS) Deli mengali di tiga DAS Paluh Besar, dengan luas total lokai yaitu di Kota Medan di Kabupaten 47.772,87 ha. Penelitian yang telah di Karo dan Deli Serdang, Propinsi Sumatera lakukan adalah di daerah sungai Sub DAS Utara. DAS Deli terdiri atas tujuh (7) Sub Deli, dimana DAS Deli berbatasan dengan; DAS yaitu Sub DAS Petani, Sub DAS Simai- Sebelah Utara dengan DAS Belawan; mai, Sub DAS Babura, Sub 218 DAS Bekala, Sebelah Selatan berbatasan dengan Sungai 
Wampu; Sebelah dengan DAS Sungai Batang Kuis.

Belawan; Sebelah Timur dengan DAS

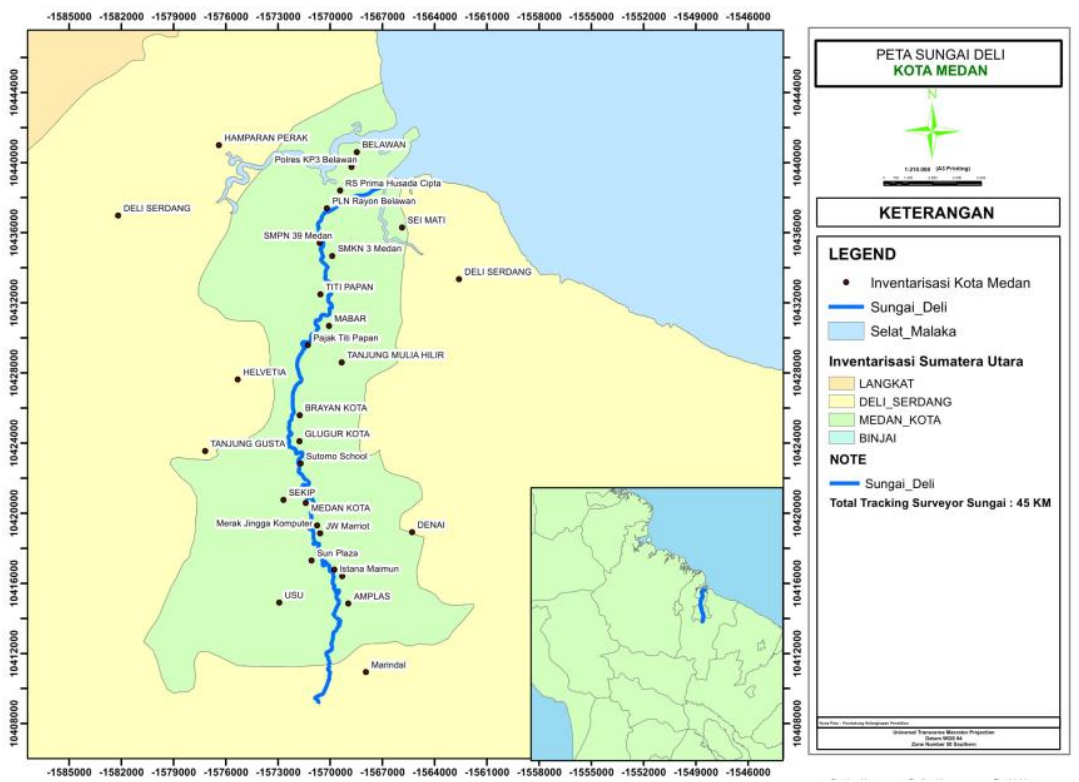

Gambar 3. Peta Sungai Deli Kota Medan

Tabel 1. Hasil Analisa Logam Berat (Pb) Daerah Aliran Sungai Deli

\begin{tabular}{ccccccc}
\hline NO & Pb (ppmI & NO & Pb (ppmI & NO & Pb (ppmI & $\begin{array}{c}\text { PP RI NO 82 TAHUN 2001 } \\
\text { (ppm) }\end{array}$ \\
\hline & Hulu & & Tengah & & Hilir & \\
\hline 1 & 0.0030 & 11 & 0,0024 & 21 & 0,0023 & 0,03 \\
2 & 0,0035 & 12 & 0,0034 & 22 & 0,0026 & 0,03 \\
3 & 0,0037 & 13 & 0,0032 & 23 & 0,0022 & 0,03 \\
4 & 0,0032 & 14 & 0,0031 & 24 & 0,0024 & 0,03 \\
5 & 0,0039 & 15 & 0,0034 & 25 & 0,0032 & 0,03 \\
6 & 0,0024 & 16 & 0,0040 & 26 & 0,0038 & 0,03 \\
7 & 0,0032 & 17 & 0,0029 & 27 & 0,0016 & 0,03 \\
8 & 0,0035 & 18 & 0,0026 & 28 & 0,0024 & 0,03 \\
9 & 0,0031 & 18 & 0,0022 & 29 & 0,0027 & 0,03 \\
10 & 0,0022 & 20 & 0,0025 & 30 & 0,0034 & 0,03
\end{tabular}

Sumber : Hasil Analisis Laboratorium 2019

Hasil analisa yang dilakukan di aliran Menurut Sitorus, H. (2004). Karena logam sungai deli yang terlihat dari tabel 1 diatasberat timbal sifat bioakumulatif, maka bisa merupakan hasil Analisa dari hulu sampaimenyebabkan konsentrasi logam tersebut hilir dimana nomor 1-10 merupakan hasilterlarut dalam air adalah kecil sedangkan Analisa hulu, nomor 11 - 20 hasil Analisapada sedimen atau bagian dasar sungai logam bagian tengah sungai deli sedangkan semakin meningkat karena adanya prosesnomor 21 sampai 30 merupakan hasil proses di perairan sungai seperti terjadinya analisis timbal sungai deli bagian hilir. proses fisika, kimia dan biologi.

Sampel yang diambil adalah air sungai deli, 
Hasil Analisa Timbal (Pb) dari hulu hal tersebut maka harus tetap di kelola hingga hilir sungai deli adalah nilai rata dengan baik karena logam berat bersifat rata $0,003 \mathrm{ppm}$ hal ini bearti pencemaran toksik atau beracun bagi tubuh manusia, logam berat timbal $(\mathrm{Pb})$ yang ada di sungai mempunyai sifat bioakumulatif dimana $\mathrm{pb}$ deli masih tergolong rendah karena yang masuk kedalam tubuh makluk hidup mengacu pada PP RI NO 82 TAHUN 2001 tidak terurai sehingga terjadi penumpukan dengan ketentuanbaku mutu untuk logam secara terus menerus dalam tubuh berat timbal yang di tentukan adalah 0,003 organisme air mengakibatkan organisme ppm. Hal ini juga di kemukakan oleh tersebut tidak mampu lagi mentolerir (Parung, 2015) dalam tulisannya Kadar kandungan logam berat timbal dalam logam berat timbal yang diperbolehkan tubuhnya (Parung, 2015). Untuk melihat dalam air untuk kehidupan akuatik tingkat pencemaran timbal di sungai deli maksimum sebesar $0.03 \mathrm{ppm}$, dalam air secara ringkas dan sederhana bisa dilihat minum maksimum $0.01 \mathrm{ppm}$, dan dalam pada gambar 4 dibawah ini.

tubuh ikan maksimum 0.02 ppm. Dengan

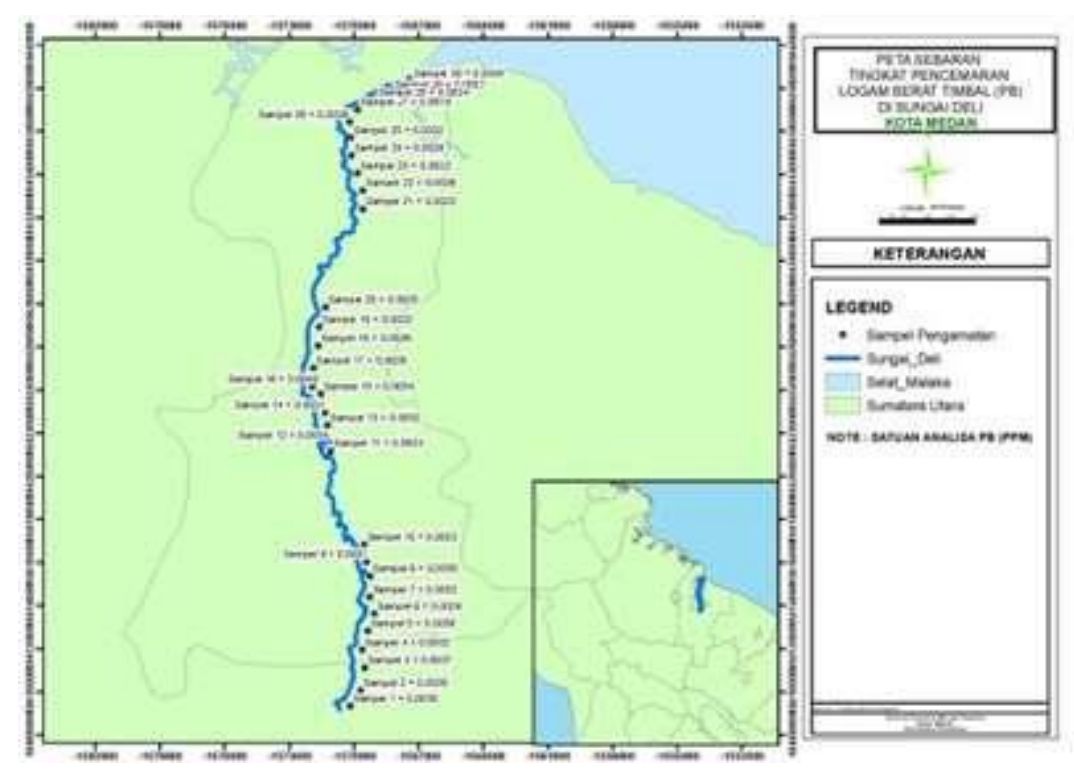

Gambar 4. Tingkat Pencemaran Logam Berat Timbal (pb) Disungai Deli Medan Sumatera Utara 


\section{SIMPULAN}

Berdasarkan hasil penelitian maka diperoleh simpulan bahwa hasil analisa logam berat timbal $(\mathrm{Pb})$ dari hulu hingga hilir sungai deli adalah nilai rata rata 0,003 ppm hal ini bearti pencemaran logam berat timbal $(\mathrm{Pb})$ yang ada di sungai deli masih tergolong rendah atau belum tercemar oleh logam berat timbal $(\mathrm{Pb})$ karena menurut PP RI NO 82 TAHUN 2001 tentang Pengelolaan Kualitas Air dan pengendalian pencemaran air baku mutu 0,03 ppm. Saran untuk peneliti logam berat lebih lanjut sebaiknya melakukan penelitian dengan menggunakan objek sedimen sungai.

\section{UCAPAN TERIMA KASIH}

Terimakasih penulis ucapakan kepada DRPM kemristekdikti atas hibah penelitian dosen pemula dengan nomor kontrak (Nomor : T / 63 / L1.3.1 / PT.01.03 / 2019), terimakasih juga kepada Rektor Universitas Prima Indonesia yang telah memberikan kesempatan untuk mengikuti program hibah ini.

\section{DAFTAR PUSTAKA}

Ali, A. (2013). Kajian kualitas air dan status mutu air sungai Metro di Kecamatan Sukun kota Malang. Bumi Lestari Journal of Environment, 13(2).

Amalia, G. R. (2013). Peran Stakeholder Dalam Implementasi Kebijakan Pengendalian Pencemaran Air Sungai Di Kota Surabaya. Media Jurnal Politik Muda, 2(2), 65-71.

Diantariani, n. P., \& putra, k. D. (2006). Penentuan kandungan logam pb dan cr pada air dan sedimen di sungai ao desa sam sam kabupaten tabanan. Ecotrophic: jurnal ilmu lingkungan (journal of environmental science), $1(2)$.

Effendi, H. 2003. Telaah Kualitas Air Bagi Pengelolaan Sumber Daya dan Lingkungan Perairan. Kanisisus. Yogyakarta

Fitri, R. (2019). PENGELOLAAN PENCEMARAN SUNGAI DELI. Jurnal Abdi Ilmu, 1(2), 8693.

Hindriani, H. (2013). Pengendalian Pencemaran Sungai Ciujung Berdasarkan Analisis Daya Tampung Beban Pencemaran. Jurnal Sumber Daya Air, 9(2), 169-184

Hutapea, S. 2012. Kajian Konservasi Daerah Aliran Sungai Deli Dalam Upaya Pengendalian Banjir Di Kota Medan. Tesis. Program Pascasarjana Fakultas Pertanian Universitas Gadjah Mada Yogyakarta

Husainy., I.A., dkk., 2014 “ Analysis Heavy Metal Lead $(\mathrm{Pb})$ Content in water and sediment in Percut River, North Sumatera. Medan. Universitas Sumatera Utara

Indonesia, R. (2008). Undang-Undang No. 18 Tahun 2008 tentang Pengelolaan Sampah. Jakarta: Sekretariat Negara.

Indonesia. (2002). Peraturan Pemerintah Republik Indonesia Nomor 82 Tahun 2001 tentang pengelolaan kualitas air dan pengendalian pencemaran air. Kementerian Lingkungan Hidup.

Liu HF, Su XY, Li X, Zhao X, Zang L, Pan WS (2006).Development of Prolonged Release Microspheres of Metformin Hydrochloride Using Ion Exchange Resins. Chin. Pharm. Sci., 15: 155-161. Mahfudloh, M., \& Lestari, H. (2017). Strategi Penanganan Limbah Industri Batik Di Kota Pekalongan. Journal of Public Policy and Management Review, 6(3), 54-69.

Nadeak, E. M. (2017). Pemeriksaan Kualitas Limbah Cair Sebelum dan Sesudah Pengolahan Air Limbah pada Limbah Cair Rumah Sakit Umum Pusat H. Adam Malik.

Parung, O. D., Litaay, M., \& Johannes, E. (2015). Analisis Kandungan Timbal (Pb) pada Sedimen, Air Laut dan Kerang Darah (Anadara granosa L.) di Perairan Pesisir Makassar. Jurnal Marina Acta Chimica, 1-10.

Prihartanto dan Budiman, E.Bayu. 2007. Sistem Informasi Pemantauan Dinamika sungai Siak. Alami, Vol. 12 Nomor 1 Tahun 2007 : 52-60.

Sugiyono. 2012. Metode Penelitian Kuantitatif Kualitatif dan R\&D. Bandung: Alfabeta

Sunarya, Y. 2007. Kimia Umum. Grafisindo. Bandung

Sitorus, H. (2004). Analisis beberapa karakteristik lingkungan perairan yang mempengaruhi akumulasi logam berat timbal dalam tubuh 
BioLink : Jurnal Biologi Lingkungan, Industri dan Kesehatan, Vol.6 (2) (2020): hal. 153-161

kerang darah di perairan pesisir timur Sumatera Utara. Jurnal Ilmu-Ilmu Perairan dan Perikanan Indonesia, 11(1), 53-60. 